\title{
Log10 50 Percent Tissue Culture Infective Dose
}

National Cancer Institute

\section{Source}

National Cancer Institute. Log10 50 Percent Tissue Culture Infective Dose. NCI

Thesaurus. Code C70488.

A potency unit for measuring infectious activity of a biologic product or infectious agent preparation equal to a base-10 logarithm of amount of product or agent preparation that causes infection in the $50 \%$ of the tissue culture-containing flasks inoculated with that dilution of infectious material in the product potency assay or pathogen activity assay. 